\title{
Studying the Potential of Calcite Dissolution on Oil Liberation from Rock Surfaces during Single-Well-Chemical-Tracer Tests by Coupling a Multiphase Flow Simulator to the Geochemical Package
}

Khaledialidusti $\mathbf{R}^{*}$ and Kleppe $\mathbf{J}$

Norwegian University of Science and Technology, Norway

\begin{abstract}
Calcite mineral dissolution has been considered to be an important mechanism for dampening the considerable $\mathrm{pH}$-variation during Single-Well-Chemical-Tracer (SWCT) tests by improving the buffer capacity of the aqueous solution. Other parameters that also could have a great effect on the geochemistry of the reservoir during the SWCT tests are water buffer capacity, soluble hydrocarbon components, and temperature.

Additionally, calcite mineral dissolution has been also presented over the last decade as an underlying mechanism for liberation of the adsorbed oil from the surface by modified salinity water injection (MSWI) in carbonate reservoirs. This contradiction of effects of calcite dissolution might pose a challenge for the accuracy of the SWCT tests in carbonates. This concern motivated us to highlight the potential of the calcite dissolution on the oil liberation from the carbonate rock surfaces during the SWCT tests by coupling a multiphase flow simulator to the geochemistry package PHREEQC.

The results show that although the calcite dissolution is marginal during injection time, it might be substantial during shut-in time which is much longer. During shut-in time, the results show that the potential of calcite dissolution on the oil liberation from the rock surfaces could be more significant at higher reservoir temperatures although initial solid calcite concentration and buffer capacity also could have an effect.

It is also clear that the $\mathrm{pH}$ of the system reaches the lowest level when the shut-in time reaches the transient time (i.e., injection and production times) and it is not changed significantly afterwards. At longer shut-in times, the additional ester hydrolysis and acid product is neutralized by the calcite dissolution and the buffer capacity of water. Therefore, the probability of the liberation of the adsorbed oil from the rock surface is higher at larger shut-in times so that test designs with shorter shut-in times and even as short as the transient time for the carbonate reservoirs is highly recommended. We hope that this study can be used to minimize the uncertainties of the SWCT tests and improve the reliability of the $S_{\text {or }}$ measurements.
\end{abstract}

Keywords: Oil; Chemical; Hydrocarbons; Minerals

\section{Introduction}

The Single-Well-Chemical-Tracer (SWCT) method has been extensively used to assess the potential of enhanced oil recovery (EOR) response based on the chromatographic separation of two different tracers in the reservoirs [1-6]. In the SWCT method, a small amount ( $1 \mathrm{wt} \%)$ of ester (e.g., ethyl acetate (EtAc)) is dissolved in the produced water (i.e., "ester bank") and then being injected and pushed out to a distance ( $3 \mathrm{~m}$ to $15 \mathrm{~m}$ ) by the produced water (i.e., "push bank"). Then, the well is shut in for a while until the ester hydrolyses $(20 \%$ to $80 \%$ ) with the formation water to produce a second tracer (i.e., alcohol; e.g., ethanol) with a different partitioning coefficient (K-value). In the previous works of Khaledialidusti et al. [6-11], all details of the SWCT method are well documented and the limitations of the method are clarified.

The limitations are: (1) limited depth of investigation, (2) fluid drift during shutting time, (3) limited ester types with different K-values and hydrolysis reaction rates ( $\mathrm{K}_{\mathrm{H}}$-values) in order to design a test with the optimal separation of the tracer profiles at different reservoir conditions, and (4) the level of $\mathrm{pH}$-variation during the test and the prediction of $\mathrm{K}_{\mathrm{H}}$-value under reservoir conditions for the numerical interpretation of the field data due to $\mathrm{pH}$ dependency of $\mathrm{K}_{\mathrm{H}}$-value.

Since hydrolysis of an ester, which is the main part of the method, leads to forming of acid as well as alcohol (ester + water $\stackrel{K_{\mu}}{\Rightarrow}$ alcohol + acid), the equilibrium state of the reservoir is disturbed and thus the $\mathrm{pH}$ changes. It is generally accepted that the $\mathrm{pH}$ of the active region where the ester concentration is high during the shut-in time would change; however, the effectiveness of this variation on the tracer profiles and the field date interpretation might not be significant for the most reservoirs.

The limitation regarding the level of $\mathrm{pH}$-variation was evaluated by Deans [12-14]. While Wellington [13] stated that "The $\mathrm{pH}$-driven rate dependence of ester hydrolysis can cause transient-generated tracers to dominate the response and make the test insensitive to oil saturation. Deans [3] stated that the acid formed during the reaction is not observed because it is neutralized by the natural base components of the reservoir.

Deans [12] concluded that at the concentration levels of esters normally used, natural buffering caused by the carbonates presents

"Corresponding author: Khaledialidusti R, Norwegian University of Science and Technology, Norway, Tel: +47 73594855; E-mail: rasoul.khaledialidusti@ntnu.no

Received March 05, 2018; Accepted March 26, 2018; Published March 31, 2018

Citation: Khaledialidusti R, Kleppe J (2018) Studying the Potential of Calcite Dissolution on Oil Liberation from Rock Surfaces during Single-Well-ChemicalTracer Tests by Coupling a Multiphase Flow Simulator to the Geochemical Package. J Pet Environ Biotechnol 9: 359. doi: 10.4172/2157-7463.1000359

Copyright: () 2018 Khaledialidusti R, et al. This is an open-access article distributed under the terms of the Creative Commons Attribution License, which permits unrestricted use, distribution, and reproduction in any medium, provided the original author and source are credited. 
Citation: Khaledialidusti R, Kleppe J (2018) Studying the Potential of Calcite Dissolution on Oil Liberation from Rock Surfaces during Single-WellChemical-Tracer Tests by Coupling a Multiphase Flow Simulator to the Geochemical Package. J Pet Environ Biotechnol 9: 359. doi: 10.4172/2157-7463.1000359

Page 2 of 9

in many reservoir water limits the $\mathrm{pH}$-variation to a relatively narrow range. Solid calcite $\left(\mathrm{CaCO}_{3}\right)$ dissolves due to the disturbance of the equilibrium state by acid generated so that calcite dissolution plays an abundant role in providing a great resistance against the $\mathrm{pH}$-variation during the test. They came to the conclusion based on only the field tests of a California turbidite reservoir including a very extensive amount of bicarbonate $\mathrm{HCO}_{3}^{-}$) level (i.e., 500 (mg/L) using UTCHEMEQBATCH.

Wellington [13] based their conclusion on the evaluation of the $\mathrm{pH}$-variation in the field tests of both carbonate-cemented California turbidite and shaly gulf coast sandstone reservoirs. They believed that the $\mathrm{pH}$-variation during the shut-in time is a concern in both sandstones and carbonates and the existence of carbonate minerals is not necessarily a factor in ensuring the narrow change of the $\mathrm{pH}$ variation.

In the work of Deans [12], the significance of the geochemical reactions as the main basis of the hydrolysis of ester was not entirely assessed due to the assumptions of the EQBATCH geochemical module. These are: (1) limiting the number of reactions rather than including the entire thermodynamically-equilibrated system, (2) local equilibrium assumption (LEA) and ignoring the kinetics of fast reacting minerals (e.g., calcite), (3) ignoring the effect of soluble hydrocarbon phase component (e.g., $\mathrm{CO}_{2}$ ) during the process, (4) ideal solution (i.e., using molalities rather than ion activities) for the water and aqueous geochemical species, and (5) no surface complexation is allowed.

It is hard to draw a conclusion based on the work of Deans and Wellington [12,13] for all reservoirs because: (1) all the effective factors on the $\mathrm{pH}$ of the reservoir were not analyzed together and they were conducted only for a particular reservoir, and (2) the geochemistry modeling was not fully evaluated due to the common assumptions of the geochemistry package used.

Due to the limitations of these works, Khaledialidusti et al. [14] reevaluated the extent to which different reservoir parameters might affect the $\mathrm{pH}$-variation during the test more comprehensively with the geochemical package PHREEQC. They concluded that calcite mineral concentration, initial buffer capacity of the reservoir, soluble hydrocarbon components, and temperature are the parameters could strongly affect the geochemistry and the $\mathrm{pH}$-variation of the reservoir during the SWCT tests so that reservoirs containing negligible solid calcite, weak buffer capacity and soluble hydrocarbon components at high temperature provide a weak resistance against the $\mathrm{pH}$-variation during the test. However, this concern is much smaller in formations with large amounts of carbonate cement (i.e., carbonates) containing heavy buffer capacity and soluble hydrocarbon components at low temperature. It was showed that the equilibrium state disturbance of the active region might lead to a $\mathrm{pH}$-variation even higher than 2.5 units for high temperature reservoirs with weak buffering capacity during shut-in time. Additionally, it leads to the dissolution of fast reacting minerals (e.g., calcite) in reservoirs during the SWCT test.

To the best of our knowledge, previous researchers unanimously agree that calcite dissolution is a worthy reason to provide an additional resistance against $\mathrm{pH}$-variation by improving the buffer capacity of the aqueous solution. However, calcite dissolution during the test might be resulting in other concern that is studied in this paper.

In the last decades, MSWI has been presented as an emerging EOR technique that has attracted significant attention. From the large numbers of research papers on the MSWI method in carbonate rocks, the wettability alteration of the carbonate surface to mobilize oil is interpreted with two main underlying mechanisms. These are: (1) dissolution of calcite or anhydrite [15-17], (2) surface-charge alteration [18]. It is also interpreted with the combination of both mechanisms $[19,20]$.

On one hand, calcite dissolution is commonly regarded as a growing phenomenon during the SWCT tests due to the equilibrium state displacement by acid produced. On the other hand, calcite dissolution is also introduced as an underlying mechanism to wettability alteration and oil liberation from the carbonate rock surfaces. This inconsistency motivated us to study the potential of calcite dissolution on the oil mobilization during the SWCT tests in carbonates, since the oil mobilization during the test could cause an error for the calculation of the oil saturation $\left(\mathrm{S}_{\mathrm{or}}\right)$.

The main question is: "If calcite dissolution is causing a dampening of the $\mathrm{pH}$-variation by neutralizing acid generated during the SWCT tests, could it also liberate the adsorbed oil from the rock surfaces?" In this paper, this question is addressed quantitatively by coupling a two-phase flow simulator with the geochemistry package PHREEQC.

A two-phase transport simulator based on Buckley-Leverett (BL) equation to expand the PHREEQC capability from single phase to multi-phase is coupled with IPhreeqc (i.e., an open-source module of the PHREEQC) to provide an interface for the efficient communication between a client simulator and the geochemical package [21,22]. BLIPhreeqc provides a two-phase and one-dimensional flow simulator for modeling the complete geochemical reactions. The essential reactions involved in the coupled BL-IPhreeqc simulator that affect the geochemistry of the reservoir during the SWCT test are given in Appendix A. More details of the BL-IPhreeqc were explained in the work of Khaledialidusti et al. and de Bruin [14,23].

\section{Research Methodology}

\section{Potential of calcite dissolution: Effect of geochemistry}

The positive charge of carbonate rock surfaces (e.g., calcite as the most common mineral in carbonates) and the negative charges of acidic oil components are caused more oil-wet surfaces. In fact, the adsorbed oil could liberate from the surface by changing the wettability towards more water-wet surface. It is widely believed that the MSWI in carbonates leads to changing the wettability through geochemistry of the solution [15,18-20,24-26]. Indeed, the main phenomenon behind the MSWI to mobilize oil is attributed to the disturbance of the equilibrated system among crude oil, brine, and rock (COBR). This disturbance starts a geochemical reaction that dissolves calcite or anhydrite, leading to a fresh surface with a change of the wettability towards more water-wet and hence, liberating the adsorbed oil from the surface (Figure 1). In fact, calcite dissolution occurs when in contact with the aqueous phase. Therefore, the hydrocarbon phase might affect the dissolution consequences by coating the rock surface and then leading to the reduction of the effective surface area.

At equilibrium state, solid calcite is not dissolved so that the solution compositions do not change with time. At this condition,
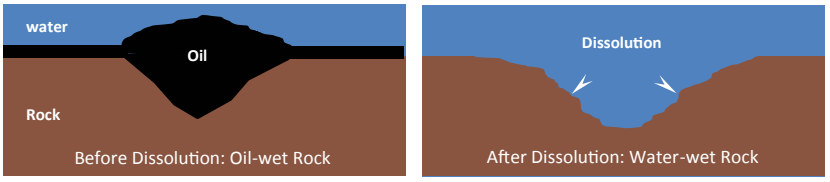

Figure 1: Schematic of wettability alteration by dissolution. 
Citation: Khaledialidusti R, Kleppe J (2018) Studying the Potential of Calcite Dissolution on Oil Liberation from Rock Surfaces during Single-WellChemical-Tracer Tests by Coupling a Multiphase Flow Simulator to the Geochemical Package. J Pet Environ Biotechnol 9: 359. doi: 10.4172/2157-7463.1000359

Page 3 of 9

the concentration of the different species in the fluid is determined by the equilibrium constants. Calcite dissolution will take over if the equilibrium state of the reservoir is displaced by changes in water compositions, temperature, buffer capacity and $\mathrm{pH}$ of the system, solution $\mathrm{CO}_{2}$, and specific surface charge. Coto [27] showed that the calcite solubility decreases significantly with temperature. Dolgaleva [28] studied the effect of $\mathrm{pH}$ on the calcite dissolution numerically. The results showed that the dissolution rate increases with decreasing $\mathrm{pH}$. $\mathrm{CO}_{2}$ becomes aqueous when in contact with water and it increases the calcite dissolution rate. This notion could also be explained with the equilibrium equation of calcite dissolution (Appendix B) in which calcite dissolution increases with higher hydrogen concentration in the fluid. These observations are in line with the work of Khaledialidusti et al. $[10,29]$.

The dissolution of solid calcite by the MSWI in carbonate oil reservoirs leads to releasing calcium and carbonate ions $\left(\mathrm{CaCo} 3(\right.$ solid $\left.) \Rightarrow \mathrm{Ca}^{2+}+\mathrm{CO}_{3}^{2-}\right)$ Calcite dissolute if the solution is under-saturated of either calcium or carbonate ions. Significance of the kinetics of calcite dissolution to determine how fast the dissolution process reaches equilibrium state was studied by Khaledialidusti et al. $[10,29]$. Kinetics does not play a role for the calcite dissolution when a system reaches equilibrium at a certain time. In our previous study [29], it was reported that the solution quickly reaches equilibrium state (saturated condition) a few meters away from the wellbore where the ion composition of the injection water inhibits further dissolution of the rock matrix since the calcite dissolution is a fast rate reaction. No improved oil recovery due to MSWI is observed in large scales when surface reactions are excluded from the model. The reason is that if the underlying mechanism depends solely on the calcite dissolution then the injected water becomes saturated by ions after penetrating only small distance into the reservoir. Hence, no more dissolution and subsequently no more wettability alteration occur afterwards. Such equilibrium is not expected in laboratory experiments due to the smaller scales. The notion of the kinetics of calcite dissolution by the MSWI in carbonate oil reservoirs is also proved by Korrani and Mahani $[15,20,26]$. They believed that the positive MSWI in carbonate reservoirs where there is no dissolution away from the wellbore is related to surface charge change.

Although the solution reaches the equilibrium state in carbonate reservoirs by the MSWI and calcite might not dissolute away from the wellbore, the hydrolysis reaction during the SWCT test (mainly shut-in time) disturbs the equilibrium state of the chemical environment in the active region where the ester concentration is more. This displacement of the equilibrium state reduces the $\mathrm{pH}$ of the solution and it might provide a condition leading to calcite dissolution.

Although the $\mathrm{pH}$ of the reservoir might decline during the SWCT tests, it is required to know the extent to which $\mathrm{pH}$-variation is significant enough for the calcite dissolution in reservoirs. In this study, calcite dissolution is assumed as the solely underlying mechanism for wettability alteration in order to study the effect of the equilibrium state disturbance on the calcite dissolution during SWCT method. How the probable displacement of the equilibrium state during the test could affect the surface-charge of the rocks is the objective of the future work, where the surface-complexation models are needed.

It is worth noting that the diffusion of hydrogen ions from the bulk solution through the diffusion boundary layer (DBL) to the surface and conversely the dissolution productions from the surface through the DBL to the bulk solution are two limiting processes on the dissolution rate. Therefore, the dissolution rate is not fully dependent on $\mathrm{pH}$ of the bulk, but also on the mass transport between the bulk and surface through the DBL. However, if the $\mathrm{pH}$ of the bulk solution decreases, the diffusion rate of hydrogen ions through the DBL increases, and as a result the hydrogen ions concentration at the surface will increase which leads to more calcite dissolution.

\section{Modeling of wettability alteration by calcite dissolution}

In order to study the extent to which the equilibrium state displacement during the SWCT tests might affect the calcite dissolution and its potential on oil liberation from the rock surface, the wettability alteration is interpolated dynamically in the coupled BL-IPhreeqc simulator as a function of calcite dissolution using the following equation:

$$
\theta=\frac{\xi_{\max }-\xi(x, t)}{\xi_{\max }-\xi_{\min }}
$$

Where, $\xi(X, t)$ is the solid calcite concentration in each gridblock, $\xi_{\max }$ is the upper amount of solid calcite concentration at which no wettability alteration would occur above that. Indeed, this value is used for the beginning of the wettability alteration from the oil-wet condition. $\xi_{\min }$ is the lower amount of solid calcite concentration at which enough amount of calcite should be dissolved for the end of the wettability alteration and making the rock surface completely waterwet. These upper and lower limits are the matching parameters.

The equilibrated data and the amount of solid calcite of all gridblocks are calculated in each time step using the PHREEQC geochemical solver. Then, using the value of $\theta$ calculated from Eq. 1, the altered relative permeabilities and capillary pressure for each gridblock may be determined by interpolating between the two relative permeability and capillary pressure sets of two different wettability conditions:

$$
\begin{aligned}
& k_{r l}^{\text {altered }}=(1-\theta) \mathrm{k}_{r l}^{\text {oil-wet }}+\theta k_{r l}^{\text {water-wet }} \\
& P_{r l}^{\text {altered }}=(1-\theta) P_{c}^{\text {oil-wet }}+\theta P_{c}^{\text {water-wet }}
\end{aligned}
$$

Figure 2 shows two different relative permeability sets of the initial and the final wettability states of a carbonate rock. These are taken from Korrani et al., so that wettability was altered due to the MSWI in a coreflood experiment in a carbonate core. Initial relative permeabilities are considered for the oil-wet system and the final state is considered as a more toward water-wet system due to calcite dissolution. The initial water saturation $\left(\mathrm{S}_{\text {wir }}\right)$ is 0.24 and 0.2 for oil-wet and water-wet systems and the residual oil saturation $\left(\mathrm{S}_{\text {or }}\right)$ is 0.42 and 0.21 for the initial and altered relative permeabilities, respectively.

These sets are applied in the coupled BL-IPHREEQC simulator in order to study the potential of calcite dissolution on the oil liberation from the carbonate rock surface during the SWCT tests. The remaining
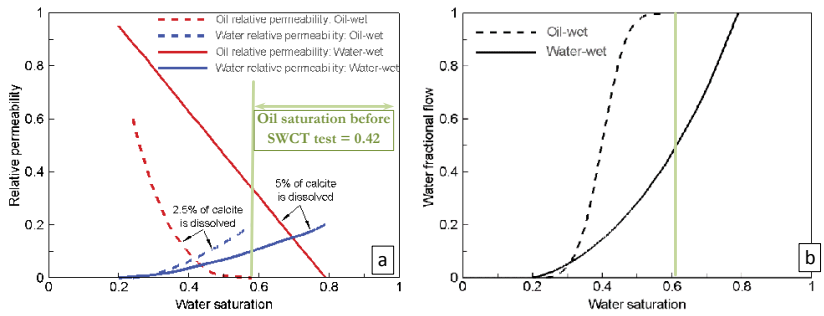

Figure 2: Relative permeabilities (a) and water fractional flows (b) for the two wettability conditions [20]. 
Citation: Khaledialidusti R, Kleppe J (2018) Studying the Potential of Calcite Dissolution on Oil Liberation from Rock Surfaces during Single-WellChemical-Tracer Tests by Coupling a Multiphase Flow Simulator to the Geochemical Package. J Pet Environ Biotechnol 9: 359. doi: 10.4172/2157-7463.1000359

Page 4 of 9

oil saturation of the systems is assumed to be 0.42 (end of oil-wet system) where no oil is recoverable by the SWCT tests if there is no calcite dissolution. However, the oil might be liberated from the surface if calcite dissolute that is the only mechanism for the wettability alteration to water-wet system.

As stated, the amounts of calcite dissolution at which wettability alteration is started and ended $\xi_{\max }$ and $\xi_{\text {min }}$ are the tuning parameters. Based on the study of Korrani [20] performed on the wettability alteration of a carbonate rock, the wettability alteration was started by the dissolution of $2.5 \%$ of initial solid calcite and a complete waterwet surface was accomplished by the dissolution of $5 \%$ of initial solid calcite. Here $\xi_{\max }$ and $\xi_{\min }$ have been set to the values at which the wettability alteration is started and ended when $2.5 \%$ and $5 \%$ of initial solid calcite is dissolved, respectively. Although these values are not representative for all cases, they have been used only to highlight the potential of calcite dissolution on the oil liberation during the SWCT tests. The water fractional flow is also calculated for these two relative permeability sets (Figure 2 ).

\section{Could calcite dissolution cause uncertainty for the SWCT tests?}

In a previous study [14], it was reported that the displacement of the equilibrium state of the active region is more significant at higher reservoir temperatures including weaker buffer capacity (i.e., carbonate and bicarbonate). It was also shown that higher reservoir temperature intensifies the disturbance of the equilibrium state by forming more acetate ions resulting from the greater $\mathrm{K}_{\mathrm{H}}$-value of ester and hence more calcite dissolute during the test. However, dissolution reaction for solid calcite is exothermic in which higher temperatures are favoring the solid phase over dissolved ions; as opposed to most minerals where less solubility is observed with decreasing temperature due to endothermic dissolution reaction [30,31]. Indeed, carbon dioxide $\left(\mathrm{CO}_{2}\right)$ is also less soluble at higher temperatures, which leads to favoring the solid phase over dissolved ions.

Here, in order to highlight the potential of calcite dissolution on the oil liberation from the rock surfaces during the SWCT tests, the system including calcite mineral concentration and with almost moderate buffer capacity in higher temperatures has been studied using the coupled BL-IPhreeqc simulator in the following.

It should be noted that since a soluble hydrocarbon phase component (i.e., $\mathrm{CO}_{2}$ ) always leads to improving carbonate concentration in the aqueous phase, it is crucial to include the effect of the soluble hydrocarbon phase components (i.e., $\mathrm{CO}_{2}$ ) on aqueousrock geochemistry. All the necessary reactions described in Appendix A are included in this study.

Calcite is assumed to be the only solid present in the system. Considering the kinetics of calcite dissolution rather than LEA for studying the geochemistry in the SWCT tests was recommend by Khaledialidusti [14]. It was shown that since the hydrolysis reaction of the ester disturbs the equilibrium of the system continually by generating acid in a period of almost 5-10 days, the kinetics of fast reacting minerals (e.g., calcite) might be significant for modeling the SWCT tests. For this reason, in this study, the kinetic dissolution of calcite is programmed $[32,33]$.

The equilibrated solution is dissolved with EtAc ( $1 \mathrm{wt} \%)$ as the "ester bank" and then it is injected for 0.5 days. Then, this slug is pushed by the equilibrated water for 0.5 days more as the "push bank". Next, the injection is stopped for 4 days based on the "two-times rule" (i.e., shut- in time is twice the transient time). Reservoir pressure is considered to be 100 (atm) with soluble hydrocarbon phase (i.e., $\mathrm{CO}_{2}$; $\mathrm{Pr}=100$ and $\mathrm{PCO}_{2}=0.65(\mathrm{~atm})$. The $\mathrm{K}_{\mathrm{H}}$-value of EtAc is also programmed to account for the dependency of the $\mathrm{K}_{\mathrm{H}}$-value on the $\mathrm{pH}$ (Appendix A).

The concern regarding the oil mobilization by the calcite dissolution during the SWCT tests is investigated in a system including the solid calcite concentration of 0.1 (mol/ $/ \mathrm{kg}$ water) at $100^{\circ} \mathrm{C}$ as a base case. Since the hydrocarbon components coat the mineral surfaces and then leading to the reduction of the effective surface area contacting with aqueous water, the reservoir including the solid calcite concentration of 0.075 (mol/ $/ \mathrm{kg}$ water) is also studied at the same temperature of $100^{\circ} \mathrm{C}$ (Case \#1). In addition, in order to evaluate the effect of reservoir temperature on the problem, the base case at $130^{\circ} \mathrm{C}$ is also evaluated (Case \#2).

The ion compositions of equilibrated water resulting from the contact of neutral water (i.e., initial solution with $\mathrm{pH}$ of 7 containing sodium, calcium, and magnesium chloride $\left(\mathrm{NaCl}, \mathrm{CaCl}_{2}\right.$, and $\left.\mathrm{MgCl}_{2}\right)$ and ionic strength of $0.47(\mathrm{~mol} / \mathrm{kg}$ water $)$ ) with solid calcite at $\mathrm{P}_{\mathrm{r}}=100$ and $\mathrm{PCO}_{2}=0.65$ (atm) are calculated by the use of the batch calculation of PHREEQC for these cases. It is worth noting that ion compositions especially calcium could affect the calcite dissolution rate, but it is negligible compared with the effect of bi $\mathrm{Pr}=100$ and $\mathrm{PCO}_{2}=0.65$ (atm) carbonate and temperature on the problem. Here, a system including almost moderate buffer capacity and high temperature with a particular calcium concentration is taken into account. The ion compositions of initial and equilibrated water are given in Table 1.

In the equilibrated water, while the concentration of initial water compositions has not been changed considerably, the buffer capacity of the solution (i.e., $\mathrm{HCO}_{3}^{-}$) has been improved leading to the change of $\mathrm{pH}$ to 6.2 (more acidic) for the base case and Case \#1. The buffer capacity for Case $\# 2$ at higher temperature of $130^{\circ} \mathrm{C}$ has been less improved (i.e., $207(\mathrm{mg} / \mathrm{L})$ compared with two other cases due to the effect of temperature on the calcite and $\mathrm{CO}_{2}$ solubility as stated above.

For a more comprehensive explanation, the test results are evaluated during two main periods: (1) injection time for two different periods of end of "ester bank" and "push bank" times, and (2) shut-in time for four different periods with 1-day interval.

\section{Base case}

In this section, the results of the $\mathrm{pH}$-variation, calcite saturation index (SI), calcite dissolution (\%), and $\mathrm{S}$, for the base case during the test are evaluated. The modeled $\mathrm{pH}$-variation is shown in Figure 3. As it can be seen, during injection time, the $\mathrm{pH}$-variation is less at the end of injection compared with the shut-in times at the active region. The results show that there is a minor difference in the $\mathrm{pH}$ of the system after the shut-in times longer than 1 day. Indeed, 1 day is enough time for the system to reach the lowest level of $\mathrm{pH}$ during shut-in time due to the ester hydrolysis reaction. In longer shut-in times, the additional ester hydrolysis and acid product is neutralized with the calcite dissolution and the buffer capacity of the system so that the $\mathrm{pH}$ of the system is not changed significantly.

Figure 4 illustrates calcite SI during the test which is a valuable measurement for studying whether the chemical environment is saturated, under-saturated, or supersaturated with respect to the given mineral. According to the SI definition given in Appendix C, a system is: (1) under-saturated if SI is negative leading to the mineral dissolution; (2): supersaturated if SI is positive leading to the mineral precipitation; and (3) at equilibrium if SI is zero so that LEA is a valid approach. 
Citation: Khaledialidusti R, Kleppe J (2018) Studying the Potential of Calcite Dissolution on Oil Liberation from Rock Surfaces during Single-WellChemical-Tracer Tests by Coupling a Multiphase Flow Simulator to the Geochemical Package. J Pet Environ Biotechnol 9: 359. doi: 10.4172/2157-7463.1000359

Page 5 of 9

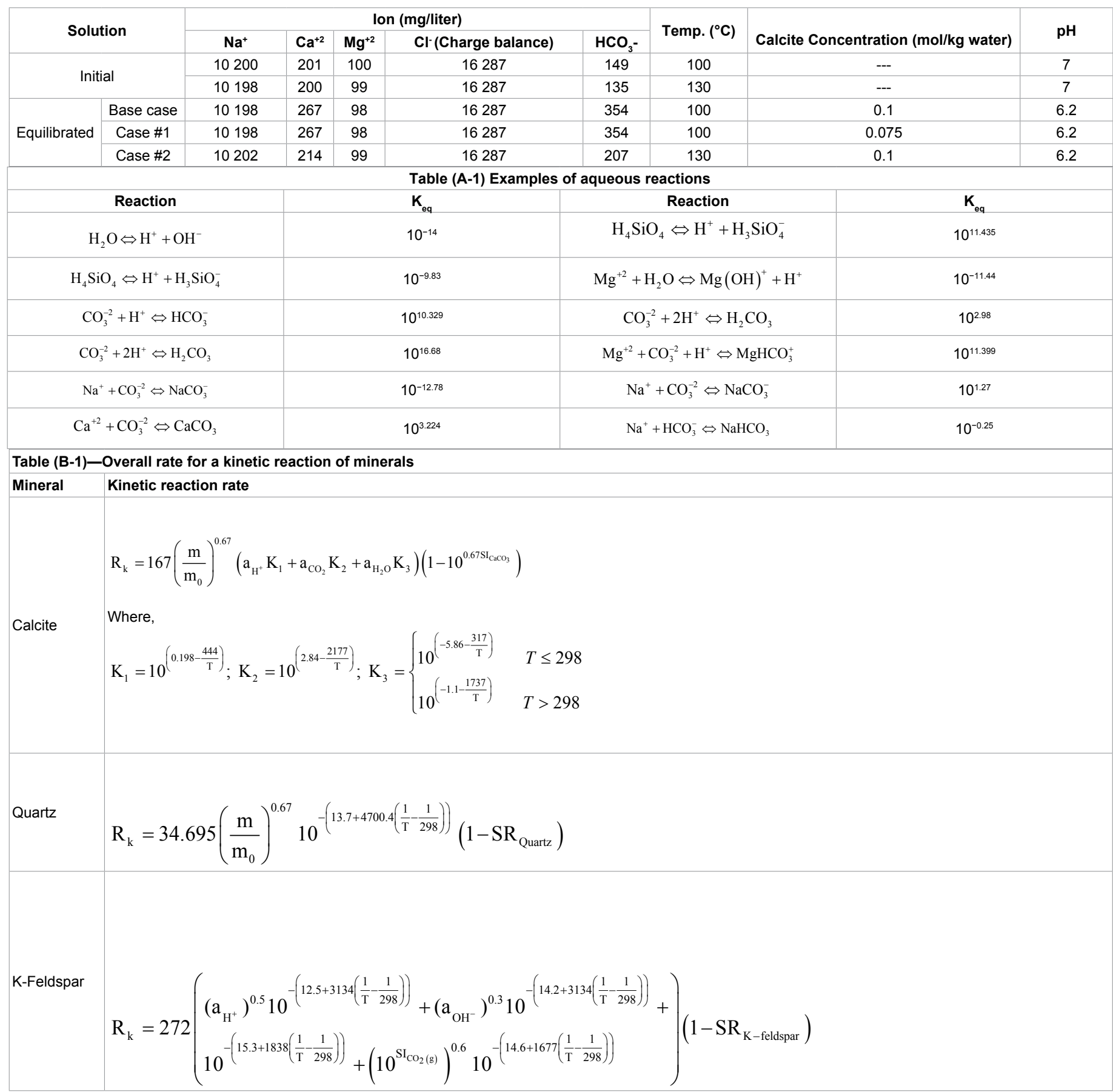

Table 1: Ion compositions of initial and equilibrated water (A-1): Examples of aqueous reactions (B-1): Overall rate for a kinetic reaction of minerals.

As it can be seen, the system has become under-saturated in the active region due to ester hydrolysis reaction which led to the equilibrium state disturbance. During injection time, the potential of calcite dissolution is not significant because of the short time of this period. Also, the system is closer to the equilibrium state due to less violation of the equilibrium state resulting in a less negative calcite SI profile.

During shut-in time, however, the system is becoming more undersaturated which is a result of the strengthening of the potential of calcite dissolution. As can be seen, after 1-day shut-in time, calcite SI reaches the lowest level (almost -1.5) and calcite mineral is exposed to the largest potential of dissolution. The solution is approaching the equilibrium state (saturated condition) at longer shut-in times. The reason is the calcite dissolution which is a fast rate reaction and increases calcium and bicarbonate ions. It is leading to buffer capacity improvements and the system is approaching the equilibrium state of the aqueous solution while ester is hydrolyzing and more acid is producing. Therefore, the potential of calcite dissolution is more significant at the beginning of the shut-in time and is decreasing at longer shut-in times.

Figure 5 illustrates the amount of calcite dissolution (\%) during the SWCT test. As explained above, the calcite dissolution is less during 
Citation: Khaledialidusti R, Kleppe J (2018) Studying the Potential of Calcite Dissolution on Oil Liberation from Rock Surfaces during Single-WellChemical-Tracer Tests by Coupling a Multiphase Flow Simulator to the Geochemical Package. J Pet Environ Biotechnol 9: 359. doi: $10.4172 / 2157-7463.1000359$

Page 6 of 9

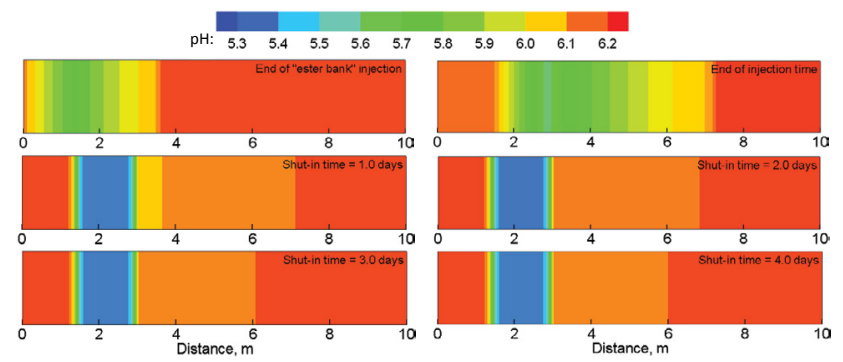

Figure 3: $\mathrm{pH}$-variation during the test for base case.

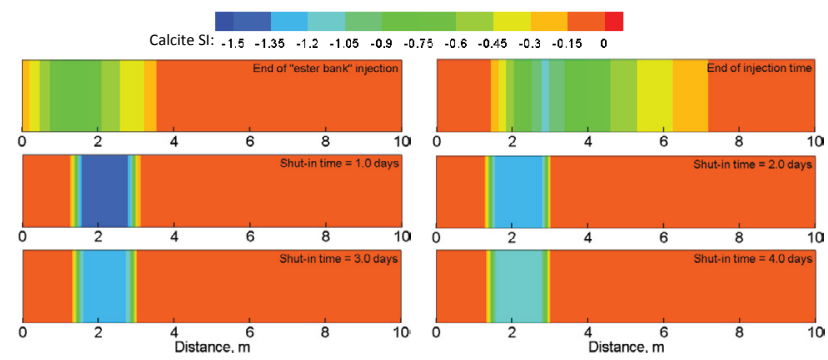

Figure 4: Calcite SI map during the test for base case.

injection times compared with shut-in time due to the short time of this period and insignificant displacement of the equilibrium state (Figure 3). As shown in Figure 5, the maximum amount of calcite dissolution in the active region is $1.8 \%$ at the end of injection time and it is up to $13 \%$ at the end of 4 days of shut-in time. During shut-in time, almost $3 \%$ of the calcite is dissolved at the end of 1 day and almost $7 \%, 10 \%$, and $13 \%$ at each interval until the end of shut-in time, respectively. Therefore, more calcite mineral is dissolved over time due mainly to the hydrolysis reaction which has led to more acid product.

From Figures 4 and 5, it can be inferred that even though the calcite mineral has the greater potential for dissolution at the beginning of the shut-in time compared with the end of shut-in time, the equilibrium state of the system is still under-saturated and more calcite is dissolved over time during this period. That is why SWCT tests with shorter shut-in time than "two-times rule" should be designed for the higher temperature carbonate reservoirs. The $\mathrm{pH}$-variation, calcite SI and the amount of calcite dissolution resulting from the equilibrium state disturbance by acid product have been investigated during the SWCT test in the base case so far. Although the results show the considerable amount of calcite dissolution during shut-in time, the amount of adsorbed oil that could be liberated from the rock surface due to the calcite dissolution is still uncertain.

In this section, the probability of the liberation of adsorbed oil from the rock surface is determined based on the work of Korrani [20] so that the oil liberation from the surface was started when $2.5 \%$ of initial solid calcite was dissolved and a complete liberation was accomplished by the dissolution of $5 \%$ of initial solid calcite. The relative permeabilities data (Figure 2) from the work of Korrani [20] has been used in this study to determine the potential of calcite dissolution on the oil liberation during the SWCT tests. The remaining oil saturation of the system is assumed to be 0.42 where no oil is recoverable by the SWCT tests in case of no calcite dissolute. The modeling of wettability alteration by calcite dissolution has been applied in BL-IPhreeqc as explained above using Eqs. 1, 2, and 3.
Since less than $2.5 \%$ of the initial calcite mineral is dissolved during injection time (Figure 5), the adsorbed oil might not liberate from the surface during this period of the SWCT test. However, during shut-in time, the calcite dissolution is improved by up to $13 \%$ over time (Figure 5) so that it might lead to liberation of the adsorbed oil from the surface. Figure 6 shows $S_{\text {or }}$ during the SWCT test. As shown, $S_{\text {or }}$ is almost the same after 2 days of shut-in time because of enough calcite dissolution to produce a complete water-wet surface. Therefore, performing the test with longer shut-in times in the higher temperature carbonate reservoirs might increase the uncertainties in the determination of the $\mathrm{S}_{\text {or }}$. We highly recommend the SWCT test is designed with shorter shut-in time than "two-times rule" and even as small as the transient time for these reservoirs.

\section{Results}

In order to examine the reservoir temperature effect on the geochemistry of the problem, Case \#2 with the same initial calcite concertation as the base case at $130^{\circ} \mathrm{C}$ (Table 1) is also assessed and the results are compared with the base case results. The dependency of the equilibrium constant $\left(\mathrm{K}_{\mathrm{eq}}\right)$ on temperature leads to changing of the equilibrated water compositions to mainly bicarbonate at 130 ${ }^{\circ} \mathrm{C}$, as given by Table 1 . One key observation is that the buffering (i.e., bicarbonate) of the equilibrated solution is less at higher temperature. This is due to the fact that solubility of calcite is decreased at the higher temperature, as it has been stated above.

The results of the amount of calcite dissolution (\%) present in four intervals of the shut-in time as well as the $\mathrm{pH}$-variation and calcite SI only at the end of 2 days shut-in time are compared in Figure 7.

The results illustrate the strong effect of temperature on the geochemistry of the system so that the amount of calcite dissolution (\%) at the end of the 4 days shut-in at $100^{\circ} \mathrm{C}$ is at the same level as at the end of the 1-day shut-in at $130^{\circ} \mathrm{C}$ (Figure $7 \mathrm{a}$ ). As has been mentioned above based on the work of Khaledialidusti et al., the displacement of

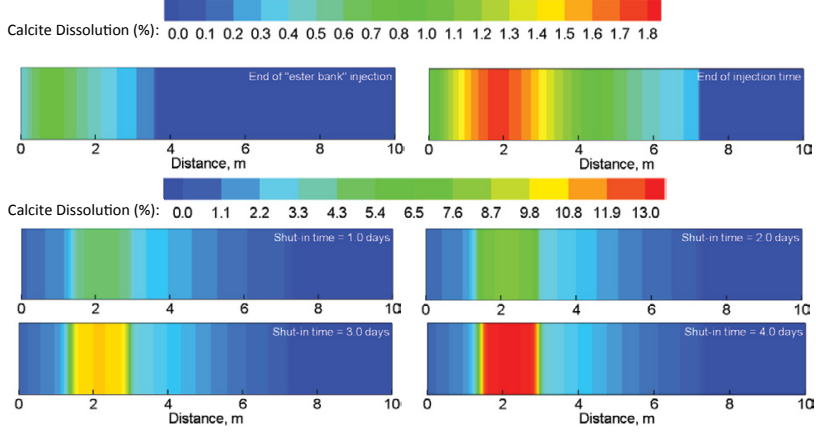

Figure 5: The amount of calcite dissolution (\%) during the test for base case.

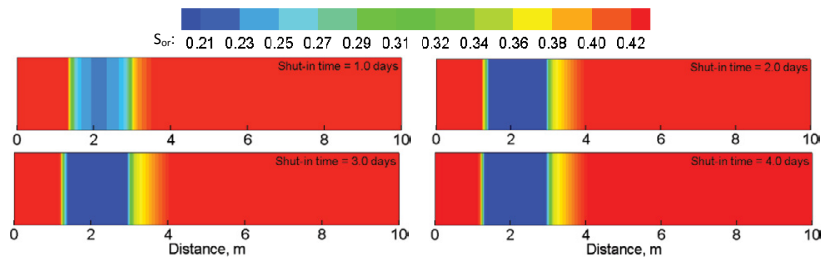

Figure 6: $\mathrm{S}_{\text {or }}$ distribution during shut-in time for base case. 
Citation: Khaledialidusti R, Kleppe J (2018) Studying the Potential of Calcite Dissolution on Oil Liberation from Rock Surfaces during Single-WellChemical-Tracer Tests by Coupling a Multiphase Flow Simulator to the Geochemical Package. J Pet Environ Biotechnol 9: 359. doi: $10.4172 / 2157-7463.1000359$

Page 7 of 9

the equilibrium state is intensified at the higher reservoir temperature due to forming of more acetate ion resulting from the greater $\mathrm{K}_{\mathrm{H}}$-value of ester (Appendix A) and hence more calcite dissolute during the test. This observation is in line with the results obtained here.

Figure $7 \mathrm{~b}$ shows that while $\mathrm{pH}$ is dropped to 5.4 at $100^{\circ} \mathrm{C}$, it is down to 4.8 at $130^{\circ} \mathrm{C}$ (i.e., more than 1.4 units from the initial $\mathrm{pH}$ ). While the improvement of the buffer capacity and more resistance against the $\mathrm{pH}$-variation is expected due to the calcite dissolution at higher temperature, unexpectedly, the $\mathrm{pH}$-variation is higher. This is mainly because of the greater $\mathrm{K}_{\mathrm{H}}$-value of ester at higher temperatures leading to forming of more acetate ion. The other observation is that the earlier drop at higher temperature, which could be due to more calcite dissolution during injection time and more hydrolysis of ester.

The results of calcite dissolution and the $\mathrm{pH}$-variation observed are supported by the results of calcite SI (Figure 7c) where, at lower temperatures, the profile of calcite SI shows that the system is closer to the equilibrium state due to much less disturbance of the equilibrium state of the system.

All in all, reservoir temperature is an effective parameter which strongly intensifies the potential of calcite dissolution on the oil liberation from the carbonate rock surfaces during SWCT tests.

\section{Initial calcite concentration}

In order to examine the effect of the solid calcite concentration in the reservoir, Case \#1 with the initial calcite concentration of 0.075 (mol/kg water) is also evaluated at the same temperature $\left(100^{\circ} \mathrm{C}\right)$ as the base case (Table 1) and the results are compared with the base case results. As it can be seen, the results of the equilibrated water calculated using batch calculation are the same as for the base case.

As in the previous section, the results of variation of the amount of calcite dissolution (\%) in four intervals of the shut-in time as well as the $\mathrm{pH}$-variation and calcite SI are compared at the end of 2 days of shut-in time (Figure 8). The results show that the initial solid calcite concentration could also affect the geochemistry of the system, but not as much as the temperature.

The results of the amount of calcite dissolution in Figure 8a show that the percentage of dissolution is increased with less initial calcite concentration so that this increase is more at a longer shut-in time.

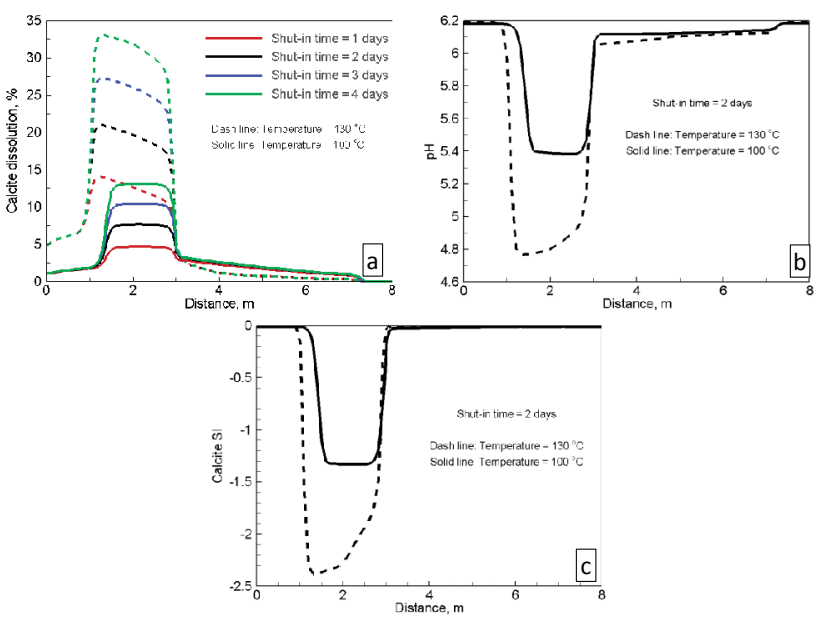

Figure 7: Temperature effect on (a): The amount of calcite dissolution (\%), (b): The pH-variation, and (c): Calcite SI.

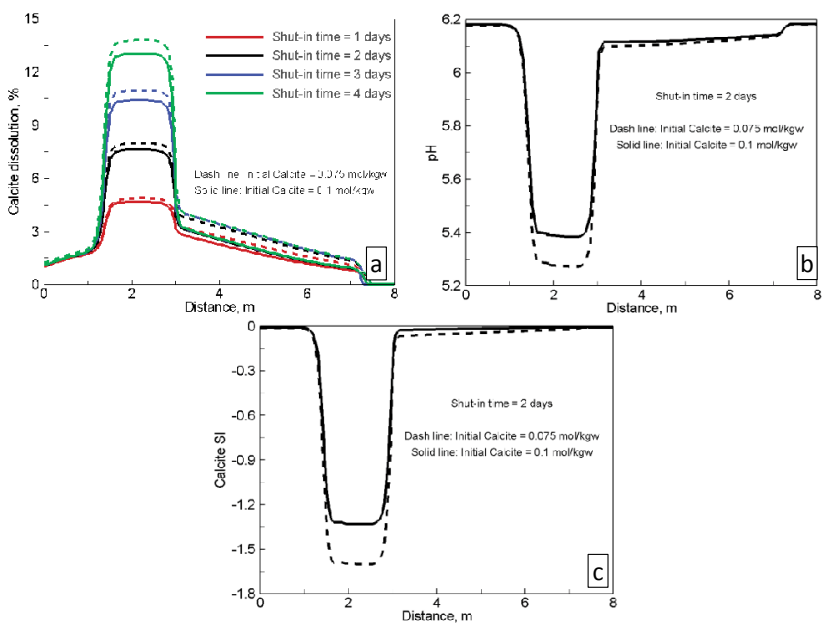

Figure 8: Initial solid calcite concentration effect on (a): The amount of calcite dissolution (\%), (b): The $\mathrm{pH}$-variation, and (c): Calcite SI.

The main reason could be interpreted from the $\mathrm{pH}$-variation results which are shown in Figure $7 \mathrm{~b}$. As can be seen, the $\mathrm{pH}$ of the system is decreasing more in the system including less calcite mineral. This is because of the fact that the equilibrium state of the system might be more disturbing in the system with less calcite mineral concentration since the dissolution of larger amounts of calcite could be a significant opposing factor against the $\mathrm{pH}$-variation. Calcite SI calculated (Figure $7 \mathrm{c}$ ) is providing an endorsement of the support for this notion so that the system including more mineral calcite concentration is closer to the equilibrium state due to much less displacement in the equilibrium state of the system.

All in all, the equilibrium state of the system including the larger amount of solid calcite might disturb less; however, a larger amount of calcite dissolution might intensify the probability of the oil mobilization from the rock surface during the SWCT tests. This is a higher concern at larger shut-in times so that the test designs with shorter shut-in times than "two-times rule" and even as low as the transient time for the carbonate reservoirs is highly recommended.

\section{Discussion}

Although calcite mineral dissolution has been unanimously recognized as one of the parameters that could provide a significant resistance against high levels of $\mathrm{pH}$-variation during the SWCT tests by improving the buffer capacity of the aqueous solution, it has been also been introduced as an underlying mechanism for liberation of the adsorbed oil from the surface by MSWI in carbonate reservoirs. This contradiction of the calcite dissolution might be encountered as a concern for the accuracy of the SWCT tests in carbonates. This motivated us to examine the potential of the calcite dissolution on the oil liberation from the rock surface during the SWCT tests in carbonates by coupling a multiphase flow simulator (i.e., BL flow simulator) to the geochemistry package PHREEQC.

It has been proved that the carbonate reservoirs containing weaker buffer capacities and soluble hydrocarbon components at higher temperatures provide a weaker resistance against the $\mathrm{pH}$-variation during the test. Therefore, in this study, the systems including two different calcite mineral concentrations of 0.075 and 0.1 (mol/kg water) at higher temperatures of 100 and $130^{\circ} \mathrm{C}$ with moderate buffer capacity are taken into consideration. 
Citation: Khaledialidusti R, Kleppe J (2018) Studying the Potential of Calcite Dissolution on Oil Liberation from Rock Surfaces during Single-WellChemical-Tracer Tests by Coupling a Multiphase Flow Simulator to the Geochemical Package. J Pet Environ Biotechnol 9: 359. doi: 10.4172/2157-7463.1000359

Page 8 of 9

\section{Conclusion}

Based on the simulation results, the conclusions to be drawn are as follows:

1. During injection time, negligible amounts of calcite could dissolute due to the short time of this period and thus cause fewer disturbances in the equilibrium state; however, it might be more significant for a shut-in time much longer.

2. During shut-in times, the $\mathrm{pH}$ level of the system is reaching its lowest level before the half of the time based on the "two-times rule" and it is not changing significantly afterwards. At longer shut-in times, the additional ester hydrolysis and acid product is neutralized by the calcite dissolution and the buffer capacity of the system. Therefore, longer shut-in times could intensify the amount of the calcite dissolution and the potential of the adsorbed oil liberation from the surface.

3. The results show that there is much less disturbance of the equilibrium state in reservoirs including higher amounts of solid calcite; however, larger amounts of solid calcite might increase the probability of oil mobilization from the rock surface during the SWCT tests. The results also show that higher reservoir temperatures could strongly strengthen the potential of calcite dissolution on the oil liberation from the carbonate rock surfaces during SWCT tests. This effect is higher for larger shut-in times so that the test designs with shorter shut-in times than "two-times rule" and even as low as the transient time for the carbonate reservoirs is highly recommended.

\section{Acknowledgments}

We thank Wouter J. De Bruin for his assistance in the coupling of BL flow and PHREEQC. This project was supported by a Joint industry research project (project no. 215660/E30), financed by the Research Council of Norway, Conoco Phillips, ENI, Engie, Lundin Norway, Restrack, Saudi Aramco, Statoil and Wintershall. Financial support as well as technological input from the research project partners is gratefully acknowledged. The authors would also like to acknowledge Institute for Energy Technology (IFE) (http://www.ife.no) who hosted the project and the leadership and the resources and staff of the Department of Petroleum Engineering and Applied Geophysics at the Norwegian University of Science and Technology.

\section{References}

1. Deans HA (1971) Method of determining fluid saturations in reservoirs. U.S Patent No. 3623824

2. Deans HA, Majoros S (1980) The single-well chemical tracer method for measuring residual oil saturation. U. S. DOE Report BC/20006-18.

3. Deans HA, Carlisle CT (2007) The single-well chemical tracer test - A method for measuring reservoir fluid saturations in situ. Petroleum Engineering Handbook, Larry W. Lake, Editor, SPE, Volume V, Reservoir Engineering and Petrophysics, pp 615-649.

4. Skrettingland K, Holt T, Tweheyo MT, Skjevrak I (2011) Snorre low-Salinitywater injection core flooding experiments and single-well field pilot. Society of Petroleum Engineers.

5. Carlisle C, Al-Maraghi E, Al-Saad B, Britton C, Fortenberry R, et al. (2014) Onespot pilot results in the Sabriyah-Mauddud carbonate formation in Kuwait using a novel surfactant formulation. Society of Petroleum Engineers.

6. Khaledialidusti R, Kleppe J, Enayatpour S (2014) Evaluation and comparison of available tracer methods for determining residual oil saturation and developing an innovative single well tracer technique: Dual salinity tracer. International Petroleum Technology Conference.

7. Khaledialidusti R, Kleppe J, Skrettingland K (2015a) Numerical interpretation of single well chemical tracer (SWCT) tests to determine residual oil saturation in Snorre reservoir. Society of Petroleum Engineers.

8. Khaledialidusti R, Enayatpour S, Badham SJ, Carlisle CT, Kleppe J (2015b) An innovative technique for determining residual and current oil saturations using a combination of Log-Inject-Log and SWCT test methods: LIL-SWCT. J. Pet. Science and Engineering, pp. 618-625

9. Khaledialidusti R, Kleppe J (2016) A new automated algorithm for designing the optimal single-well-chemical-tracer SWCT tests at various reservoir conditions. Society of Petroleum Engineers.

10. Khaledialidusti R, Kleppe $J$ (2017b) A comprehensive framework for the theoretical assessment of the single-well-chemical-tracer (SWCT) tests. J Pet Science and Engineering 159: 164-181.

11. Khaledialidusti R, Kleppe J, Tweheyo M, Skrettingland K (2017c) Mechanistic modeling of alkaline/surfactant/polymer flooding for Snorre field from corescale to larger scale of one-spot pilot. International Journal of Engineering Trends and Technology 46: 337-354.

12. Deans HA, Ghosh $\mathrm{R}$ (1994) $\mathrm{pH}$ and reaction rate changes during single-well chemical tracer tests. Society of Petroleum Engineers.

13. Wellington SL, Richardson EA (1994) Redesigned ester single-well tracer tes that incorporates $\mathrm{pH}$-driven hydrolysis rate changes. Society of Petroleum Engineers.

14. Khaledialidusti R, Kleppe J (2017d) Significance of geochemistry in singlewell-chemical-tracer tests by coupling a multiphase flow simulator to the geochemical package. SPE Journal.

15. Hiorth A, Cathles LM, Madland MV (2010) The impact of pore water chemistry on carbonate surface charge and oil wettability. Transp Porous Med 85: 1-21.

16. Yousef AA, Al-Saleh SH, Al-Kaabi A, Al-Jawfi MS (2011) Laboratory investigation of the impact of injection-water salinity and ionic content on oil recovery from carbonate reservoirs. Society of Petroleum Engineers.

17. Austad T, Shariatpanahi SF, Strand S, Black CJJ, Webb KJ (2012) Conditions for a low-salinity enhanced oil recovery (EOR) effect in carbonate oil reservoirs. Energy \& Fuels 26: 569-575.

18. Mahani H, Keya AL, Berg S, Bartels W, Nasralla R, et al. (2015) Insights into the mechanism of wettability alteration by low-salinity flooding (LSF) in carbonates. Energy \& Fuels 29: 1352-1367

19. Al-Shalabi EW, Sepehrnoori K, Pope G (2015) Geochemical interpretation of low-salinity-water injection in carbonate oil reservoirs. Society of Petroleum Engineers.

20. Korrani AKN, Fu W, Sanaei A, Sepehrnoori K (2015) Mechanistic modeling of modified salinity waterflooding in carbonate reservoirs. Society of Petroleum Engineers.

21. Parkhurst DL, Appelo CAJ (1999) User's guide to PHREEQC (Version 2): A computer program for speciation, batch-reaction, one-dimensional transport, and inverse geochemical calculations.

22. Parkhurst DL, Appelo CAJ (2013) Description of Input and Examples fo PHREEQC Version 3-a Computer Program for Speciation, Batch-reaction, One-dimensional Transport, and Inverse Geochemical Calculations.

23. De Bruin WJ (2012) Simulation of geochemical processes during low salinity water flooding by coupling multiphase Buckley-Leverett flow to the geochemical package PHREEQC. MS Thesis. Delft University of Technology. Delft, The Netherland.

24. Austad T, Strand S, Høgnesen EJ, Zhang P (2005) Seawater as IOR Fluid in Fractured Chalk. Society of Petroleum Engineers.

25. Austad T, Strand S, Madland MV, Puntervold T, Korsnes RI (2008) Seawater in chalk: An EOR and compaction fluid. Society of Petroleum Engineers.

26. Mahani H, Keya AL, Berg S, Nasralla R (2017) Electrokinetics of carbonate/ brine interface in low-salinity waterflooding: Effect of brine salinity, composition, rock type, and $\mathrm{pH}$ on and zeta potential and a surface-complexation model. Society of Petroleum Engineers.

27. Coto B, Martos C, Peña JL, Rodríguez R, Pastor G (2012) Effects in the solubility of $\mathrm{CaCO}_{3}$ : Experimental study and model description. Fluid Phase Equilibria 324: 1-7.

28. Dolgaleva IV, Gorichev IG, Izotov AD, Stepanov VM (2005) Modeling of the effect of $\mathrm{pH}$ on the calcite dissolution kinetics. Theor Found Chem Eng 39 : 614-621. 
Citation: Khaledialidusti R, Kleppe J (2018) Studying the Potential of Calcite Dissolution on Oil Liberation from Rock Surfaces during Single-WellChemical-Tracer Tests by Coupling a Multiphase Flow Simulator to the Geochemical Package. J Pet Environ Biotechnol 9: 359. doi: 10.4172/2157-7463.1000359

Page 9 of 9

29. Khaledialidusti R, Kleppe J (2017a) Significance of the kinetics of minerals in reactive-transport problems. Society of Petroleum Engineers.

30. Garrels RM, Charles LC (1965) Solutions, minerals and equilibria, Harper \& Row, New York, pp. 450.

31. Langmuir D (1997) Aqueous Environmental Geochemistry, Prentice-Hall, Inc, upper Sanddle River, NJ, pp. 600.

32. Buckley SE, Leverett MC (1941) Mechanism of fluid displacement in sands Trans. Aime p. 146.

33. National Research Council (1930) International Critical Tables (1st edn) McGraw-Hill Book Co. Inc, New York, USA. 6: 128-141. 